Research Trainee

\title{
"Youth Will Feel Honoured if They Are Reminded They Are Loved": Supporting Coming of Age for Urban Indigenous Youth in Care
}

\author{
Andrea Mellor, Surrounded by Cedar Child and Family Services, Denise Cloutier, Nick Claxton
}

\section{A R T I C L E IN F O}

Keywords:

Community-based research

Self-determination

Health and wellness

Youth engagement

Elder engagement

Coming of age

Indigenous methodologies

Arts-based methodologies

Child welfare

https://doi.org/10.32799/ijih.v16i1.33179

\begin{abstract}
A B S T R A C T
This paper presents the first phase of a community engagement project that explores (re)connecting to coming-of-age teachings grounded in Indigenous ways of knowing and doing for urban Indigenous youth in foster or away-from-home care. An intergenerational group of urban Indigenous Knowledge Holders in and around Victoria, British Columbia, Canada came together to discuss what a culturally appropriate coming of age could look like for urban Indigenous youth in care and how delegated Indigenous child and family service organizations could be involved. Four questions were discussed, and the conversations were recorded and subsequently themed. The event reflected the community's commitment to supporting youth in their coming-of-age journey. Delegated organizations, in addition to acting as legal guardians for the youth, are cultural resources for the community and help connect youth to culture in their ancestral/home and urban communities. Communities work to ensure that youth have access to safe spaces where they can self-determine their identities as they enter adulthood. (Re)connecting to coming-of-age teachings is important because the imposition of Euro-Western child welfare legislation prevented the passing of cultural teachings. Our findings are consistent with literature that indicates culturally grounded, positive-action initiatives, like traditional coming-of-age rites of passage, help youth to cultivate resilience that can support the transition to adulthood. This aligns with evidence that demonstrates intergenerational cultural continuity is protective to health and wellness for Indigenous youth.
\end{abstract}

\section{A UTHOR INFO}

Andrea Mellor, PhD candidate, Social Dimensions of Health, University of Victoria. Email: amellor@uvic.ca.

Surrounded by Cedar Child and Family Services, Victoria.

Denise Cloutier, $\mathrm{PhD}$, Department of Geography, University of Victoria.

Nick Claxton, PhD, School of Child and Youth Care, University of Victoria. 


\section{Acknowledgements}

Hay'sxw'qa si'em Lekwungen elth'tel'nexw, Hay'sxw'qa si'em Lekwungen tung'exw, hay'sxw'qa si'em Lekwungen xa'sa

Thank you Respected Place to Smoke Herring people, thank you Place to Smoke Herring people's lands, thank you Place to Smoke Herring people's sacred waters,

Thlaninulth hay'sxw'qa si 'em a'nelth hali, chay, ye'yah'sung stay'tha en 'sne i'ey'mut tung'exw, i'ey'mut xa'sa

We thank you Respected for allowing us to live, work, play on your beautiful lands, beautiful sacred waters.

We thank the youth, Knowledge Holders, and Elders who participated in the dinner and those who met with the research team before and after the dinner. Thank you to Surrounded by Cedar Child and Family Services who, in addition to guiding this project, opened their doors to this event and hosted the dinner and all the planning meetings. Surrounded by Cedar raises its hands in gratitude to those who have supported the agency over the years, to those who envisioned this organization and were instrumental in its development, and to the children, youth, and families with whom we walk each day.

We extend a special thanks to one of our project's Lekwungen Knowledge Holders who shared the Lekwung'athun territory acknowledgement with us and gave us permission to share it here. Thank you to Michelle Bucholz and Drawing Change who supported the illustration. This research is funded by a Social Sciences and Humanities Research Council Reconciliation Connection Grant and an Island Health Collaborative Grant.

\section{Introduction}

For Indigenous youth, coming of age can be described as the preparation and entrance into adulthood, when they learn about the responsibilities of providing for and sustaining their communities, and when they come into their own sources of spiritual power and learn how to respect the power of others. "Coming-of-age practices are embedded in broader belief systems of cosmological constructions, which include origin stories, explanations for the cyclical nature of creation and patterns of life, and the complex relationships between humans and the spiritual realm" (Markstrom, 2008, p. 1).

This project's community partner, Surrounded by Cedar Child and Family Services (SCCFS), advocates for (re)connecting to spirit and identity through familial, hereditary, and cultural linkages because these are the strongest protective factors for promoting safety and wellbeing amongst Indigenous people (SCCFS, 2018). The importance of accessing cultural knowledge during adolescence was emphasized in a landmark study emphasizing that measures of cultural continuity, like the passing of intergenerational teachings, are protective against Indigenous youth suicides (Chandler \& Lalonde, 1998). These protective factors buffer risks 
associated with intergenerational and colonial trauma and can be facilitated through activities including land-based learning, language programming, traditional arts and crafts, and specific to this project, coming-of-age teachings (e.g., Chandler \& Lalonde, 1998; Claxton, 2015; Flicker et al., 2014; McIvor et al., 2009).

Canada's Truth and Reconciliation Commission's (TRC) first Call to Action is to reduce the number of Indigenous children in care, including keeping children in culturally appropriate environments (TRC, 2015). While we work to achieve the goal of keeping children and youth in their home communities with the services that they need to support strong families, culturally appropriate resources are needed to support children and youth through their transition towards adulthood. Evidence shows that when youth have the autonomy to share their voices, they have higher self-esteem and a greater commitment to friends, family, community, and themselves, reducing senses of social isolation and stigma (e.g., Blanchet-Cohen et al., 2011; Chandler \& Lalonde, 1998; Suleiman et al., 2006; SCCFS, personal communication, March 2019). Yet, "systems that socialize our children are not attuned to their rich cultural heritage" (Brokenleg, 2012, p. 9), which limits ways in which qualities like personal resilience can be fostered day-today.

This paper presents the findings from the first phase of community engagement for the project: Supporting Culturally Appropriate Coming of Age Resources for Urban Indigenous Youth in Care on Vancouver Island: (Re)Connecting with Self-Determined Health and Wellness. ${ }^{1}$ This project is a positive-action initiative ${ }^{2}$ that works to embrace cultural practices as healing medicine for adolescence and the life that will follow. This project phase brought together urban Indigenous Knowledge Holders from diverse backgrounds and communities in and around Victoria, British Columbia to discuss what coming of age could look like for urban Indigenous youth in foster and away-from-home care (i.e., in care) and what the role of their legal guardians, delegated Indigenous child and family services organizations could be. Fifty-six percent of Indigenous people in Canada live in urban centres (Statistics Canada, 2011), and ensuring healing and protective teachings are accessible in urban spaces is essential to the continuity of teachings. Further, recognizing and expressing the unique cultural narratives between Nations while finding unity in shared epistemologies of "oneness" draws upon a collective resilience that can emerge in places of diverse Indigenous identities.

\section{Methods}

Leroy Little Bear said that "in the Indigenous world, knowledge is relationships" (2009, p. 8).

\footnotetext{
${ }^{1}$ The study received ethical approval from the University of Victoria and Island Health Research Ethics Boards.

${ }^{2}$ Positive-action initiative is a term created by Indigenous health activist Valerie Nicholson to highlight strengthbased measures that support positive health outcomes. This phrase replaces the word intervention, which suggests the "patient" is less involved in the decisions related to their living experience.
} 
This relationship is predicated on the fact that all Indigenous tribes - their philosophies, cultural ways of life, customs, language, all aspects of their cultural being in one way or another-are ultimately tied to the relationships that they have established and applied during their history with regard to certain places and to the earth as a whole. (Cajete, 2000, p. 4)

These connections, the aspects of one's cultural being, are the elements that coming-ofage teachings and rite of passage ceremonies seek to uphold. This project engages with complementary research methodologies that celebrate interconnectivity and relationality, Indigenous methodologies, and community-based participatory research. Relationality is central to Indigenous ways of knowing and doing and is the essence of Indigenous methodologies (Kovach, 2009; Wilson, 2008). Community-based research is "fundamentally driven by relationships" (de Leeuw et al., 2012, p. 188). Of critical importance to research relationships, it draws on the strengths and assets of the community, acknowledging the expertise community members have in their own living experience, supporting issues that are of importance to them (McIntyre et al., 2007; Mendenhall \& Doherty, 2007).

\section{Dinner Planning and Question Development}

Our preliminary planning meeting included members of SCCFS's team and allied university and Island health project co-leads. The team agreed that we needed to "call the circle in" so that the community could identify the areas of focus that would guide the project. We decided that the most appropriate way to do this was to host a Knowledge Holder's dinner that honoured Indigenous ways of knowing, sharing, and learning. During the planning meeting, the team brainstormed a list of community members who would be able to contribute to the conversation in meaningful ways. We were intentional in ensuring we invited people from various Nations across Turtle Island, aligning with the diversity that exists among the children and youth that SCCFS provides services to. We discussed the types of established relationships community members had with the team, including their involvement with SCCFS as care providers (e.g., foster parents); community-recognized Knowledge Holders (e.g., Elders); Indigenous community-based researchers (e.g., Indigenous faculty from the University of Victoria); Indigenous community-based health care providers (e.g., public health service providers); and other urban Indigenous community members (e.g., artists, mentors, etc.). We purposively identified individuals with established relationships to team members in order to manage the scale of engagement, though some participants were also welcomed based on recommendations by participants who had accepted our invitation (i.e., snowball sampling).

A second pre-event meeting established the four main research questions that would be asked during the dinner. The questions addressed four broad community relationships that youth may identify with: their guardians (i.e., SCCFS), the urban community, their home or ancestral community, and the LGBTQ2S+ community. Figure 1 presents a schematic of how the questions were conceptualized. 


\section{Figure 1}

Guiding Questions for the Sharing Circles and How They are Interrelated

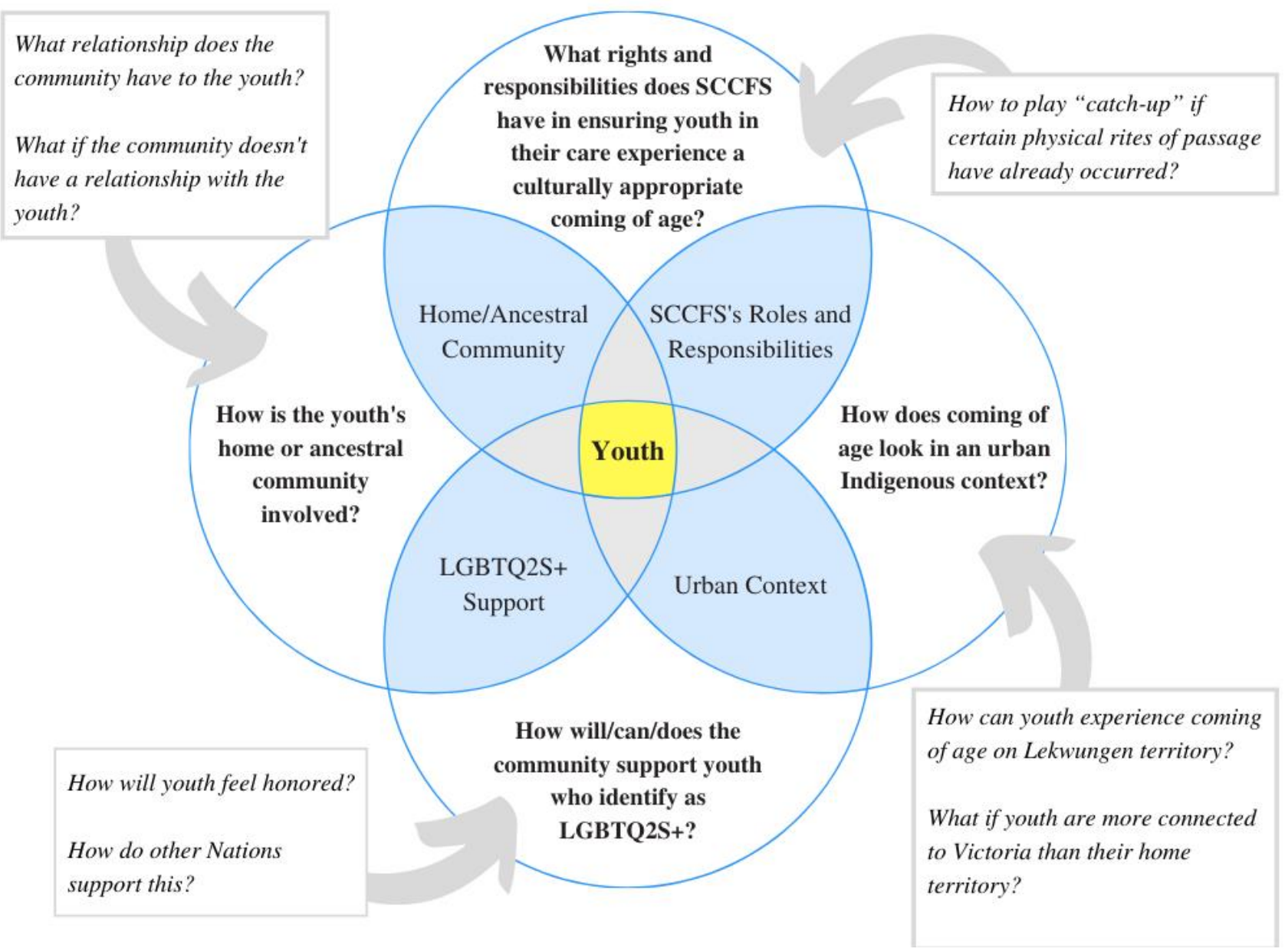

Note. This schematic shows how the four community relationships of focus are centred on the youth. The interior questions represent the overarching areas addressed during our sharing circles, while the outside questions were specific areas of interest SCCFS wished to understand based on the organization's experiences.

\section{Wisdom Catching and Gathering}

The dinner was held during spring 2019 at SCCFS's offices. An intergenerational mix of 30 individuals attended, including three Elders, four youth, and two infants. Six of the participants were SCCFS team members. Indigenous participants identified with 20 different Nations. Four of the dinner attendees identified as non-Indigenous and were present in a coordination capacity at the invitation of SCCFS and as co-researchers. 
Prior to beginning our meal, we were welcomed in Lekwungen'athun to the Lekwungen territory, Hay'sxw'qa gwns âne 'techul Lekwungen Tung'exw by a Knowledge Holder who has permission to share this responsibility. Our meal, the youth, and the evening were blessed in spoken word and in song in Hul'q'umi'num by an Elder in attendance whose lineage is tied to WSÁNÉC and Malahat Nations. Following our semi-traditional meal of Indian tacos, our facilitator initiated evening discussions by inviting round table introductions, travelling in the direction of Coast Salish protocol. Everyone was invited to share their name, a word to describe how they were feeling, and their preferred pronouns (e.g., her, she, him, her, they). Several participants shared this in their Nation's language, indicating that English words would not be adequate to convey their feelings. A discussion of the evening's proposed process followed. Each of the four questions were discussed in different locations of the office, and participants were invited to go to the "question station" of their choosing to start with and move through them at their leisure. Both a facilitator and a wisdom catcher ${ }^{1}$ were present at each station. The facilitator was an SCCFS team member who was chosen to lead the question based on their role with the organization. Wisdom catchers were non-Indigenous team members who recorded conversations at their station but did not participate in them. Conversations about each question were approximately one hour each. All groups returned to the round table following discussions, and facilitators reviewed the main points that were captured at each station. To end the event, the facilitator invited attendees to share a word to describe their feelings after having gone through the questions. This was done in the opposite direction of our opening circle, to honour the protocols of other Nations present. A final blessing closed out the evening.

Dinner attendees provided either written or verbal consent, and each participant was provided a cash gift to thank them for their time, recognize their travel, and demonstrate our appreciation for their contributions about their own experiences. Following the dinner, consent forms were scanned for record keeping, and the originals were mailed back to each participant with thank you cards expressing our appreciation for their attendance.

\section{Interpretation and Analysis}

To maintain congruency with the relational Indigenist paradigm we were working with, it was necessary to use a data analysis method that could preserve the relationships between the ideas that were uncovered at each sharing circle but recognize that some themes emerged that were more dominant than others. The metaphor of the fishing net, presented by Shawn Wilson in his book Research Is Ceremony (2008), became a framework for our analysis:

The data and analysis are like a circular fishing net. You could try to examine each of the knots in the net to see what holds it together, but it's the strings between the knots that have to work in conjunction in order for the net to function. So any analysis must

\footnotetext{
${ }^{1}$ At the request of a participant, the language of "note taking" was replaced with "wisdom catching" to decolonize the way we describe recording conversations.
} 
examine all of the relationships or strings between particular events or knots of data as a whole before it will make any sense. (p. 120)

Each question was analyzed to establish themes (knots) in order to draw out the relationships (strings) between the themes that hold their "net" together. There is significance to this analogy because within the Coast Salish territory, where this project is taking place, the WSÁNÉC reef net or SXXOLE, is an integral component of the territorial governance structure and relational worldview of the Peoples (Claxton, 2015, p. 70-71). This relational worldview maintains the one-ness or unity between the relationships of the participants, the wisdoms that they shared, and a respect for the land and laws of the territory where we held the dinner.

The wisdoms caught on paper were divided into short sections that reflected a "selfstanding passage" (Saldana, 2015, p. 8), or a unique idea or concept in the context of the larger discussion. Descriptive phrases were assigned to these passages and were specific to the question being reviewed, emphasizing the focus on individual and community assets of this project such as "peer supports" or "unique capacities." Phrases were clustered into themes (knots) prior to interpreting the ways that they interrelate and influence one another (strings).

\section{Narrative Interpretation}

The themes generated through our analysis are presented in Table 1 using a research storytelling method. This is intended to present findings in ways that "make sense, that speak to and speak with the communities in which the research takes place" (Christensen, 2012, p. 233). Storytelling was a way many participants shared their responses to the questions, which complements our methodology in that, "autobiographical narratives typically make reference to core cultural values as well as to particular [perceptions] of personal and historical time" (Kirmayer et al., 2011, p. 85). Engaging with storytelling reflects the dialogues that took place at the dinner and, more deeply, reflect the sociocultural framework within which Indigenous knowledge is shared (Little Bear, 2000). The wisdoms caught during each of the conversations have been tied together to establish our narrative "fishing net" (Table 1) as a foundation to catch the teachings from the youth as we move through this project.

\section{Graphic Recording}

The relationship between questions was summarized, reviewed by the team, and submitted to an illustrator who specializes in visually expressing conversations. The illustration developed is a visual depiction of the themes uncovered during the dinner and is arranged similarly to the research questions (i.e., the youth being surrounding by their communities; Figure 1). The intention of this medium is to show the breadth of the conversations in an accessible way that invites the viewer to engage with our findings, but in a way that is unique and personal to their own individuality. This is consistent with our project's engagement with Indigenous knowledge sharing, where the learner takes what they are able to in that moment in time as opposed to a teacher telling the learner what they should be seeing. The first draft was presented to the team where we discussed the symbology, feelings evoked from the images, and how certain images did or did not represent the tone of our conversations. Three iterations of the 
draft occurred before being finalized (see Figure 2). The original drawing will reside at SCCFS, but a digitized version was distributed to the participants.

\section{Findings: Tying the Net}

Each conversation revealed complexities that could be faced by each of the communities identified in the research questions. The narrative and illustration weave the themes revealed in our conversations and reflects the significance of centring the youth in our conversations, and how these conversations happen across diverse landscapes, histories, communities, and generations.

For example, SCCFS says that the youth are the fire of the community, and it is the community's responsibility to keep the fire lit. This is illustrated near the centre of Figure 2 as youth sitting around the fire, and metaphorically, seeing themselves in or as the fire. They can safely engage with this concept because the SCCFS community or "Cedar" has worked to cultivate a safe and protected space. This is woven into the story by saying, "The Cedar has gathered the youth around the fire / The Cedar protects them" (Table 1). This reflects not only SCCFS's responsibility as legal guardians but also their roles as aunties and uncles, vested in promoting safety and well-being of Indigenous Peoples more broadly.

The story and the visual imagery reflect the contributions of the Knowledge Holders and are informed by many different visions of Indigeneity and coming of age unique to each person's living experience, but still united in a commitment to support the youth community. You, the reader, may wish to use the story in Table 1 as a guide through the illustration or alternatively, you may wish to develop your own narrative, one that reflects your understanding, positionality, and connection to Indigenous coming of age.

\section{Table 1}

\section{Cedar's Story: A Narration of Themes}

\begin{tabular}{ll}
\hline Cedar Story & Theme \\
\hline $\begin{array}{l}\text { The Cedar has gathered the youth around the fire. } \\
\text { The Cedar protects them. }\end{array}$ & $\begin{array}{l}\text { SCCFS is a cultural hub (Q1) } \\
\text { The Cedar teaches them to look in the fire. } \\
\text { The youth see themselves; they are the fire. }\end{array}$ \\
\hline $\begin{array}{l}\text { Cedar teaches the youth about the land, } \\
\text { beyond the forest is the city of Victoria. }\end{array}$ & $\begin{array}{l}\text { SCCFS's coming-of- age } \\
\text { But Victoria is a new place. }\end{array}$ \\
$\begin{array}{l}\text { This is Coast Salish territory and it is an old place. } \\
\text { Old, since the beginning of time. }\end{array}$ & \\
\hline
\end{tabular}




\section{Table 1 con't}

\begin{tabular}{|c|c|}
\hline $\begin{array}{l}\text { Cedar teaches the youth, } \\
\text { "We are in the home of the Lekwungen'athun } \\
\text { speaking people; } \\
\text { we must honour that by respecting their ways, their } \\
\text { protocols." } \\
\text { Cedar tells them, "we are learning together how to do } \\
\text { this in a good way." }\end{array}$ & $\begin{array}{l}\text { Stronger Together }(\mathrm{Q} 1) \\
\text { Inter-Nation relationships (Q3) }\end{array}$ \\
\hline $\begin{array}{l}\text { "You are coming of age," says Cedar, } \\
\text { "Every day you pass through time, just like your } \\
\text { ancestors before you. } \\
\text { And while your ancestors walk through this journey } \\
\text { with you from the spirit world, } \\
\text { Your family walks through it with you too. } \\
\text { Even if they are in different places than here; } \\
\text { mountains, plains, lakes... } \\
\text { You can see them by looking in the fire, } \\
\text { We are all connected." }\end{array}$ & $\begin{array}{l}\text { Coming-of-age teachings take a } \\
\text { community }(\mathrm{Q} 2)\end{array}$ \\
\hline $\begin{array}{l}\text { Cedar says, "we have teachers too." } \\
\text { We learn from our Elders, we learn from our ancestors, } \\
\text { your families. } \\
\text { We learn the most from you. } \\
\text { We are learning how to give you a good coming of } \\
\text { age, } \\
\text { connected to teachings that will make you strong, } \\
\text { passed through ceremony that is right for you. }\end{array}$ & $\begin{array}{l}\text { Coming-of-age teachings take a } \\
\text { community (Q2) }\end{array}$ \\
\hline $\begin{array}{l}\text { There are many teachings. } \\
\text { As many teachings as there are stars. } \\
\text { But just like you can see a sky of stars if you stand in } \\
\text { one place, } \\
\text { From this city, beyond the forest, we can see so many } \\
\text { teachings. }\end{array}$ & Inter-Nation relationships (Q3) \\
\hline $\begin{array}{l}\text { You are this fire. } \\
\text { We will work to keep it lit. } \\
\text { Because one day you will be the fire keeper. } \\
\text { When you are ready, when it is your time. } \\
\text { You carry these wisdoms within you. } \\
\text { As does your family. } \\
\text { And your community. } \\
\text { But we need to weave them together. } \\
\text { Because the fabric of the teachings frayed a little. }\end{array}$ & $\begin{array}{l}\text { Coming of age takes a community } \\
\text { (Q2) }\end{array}$ \\
\hline $\begin{array}{l}\text { You will decide how to receive these teachings. } \\
\text { When you step out of the forest. } \\
\text { But we are all listening. } \\
\text { When you are ready to tell your story. }\end{array}$ & Youth's journey (Q2) \\
\hline
\end{tabular}


Figure 2

Illustrated Graphic to Depict the Interpretation of Themes Derived from the Knowledge Holder's Dinner

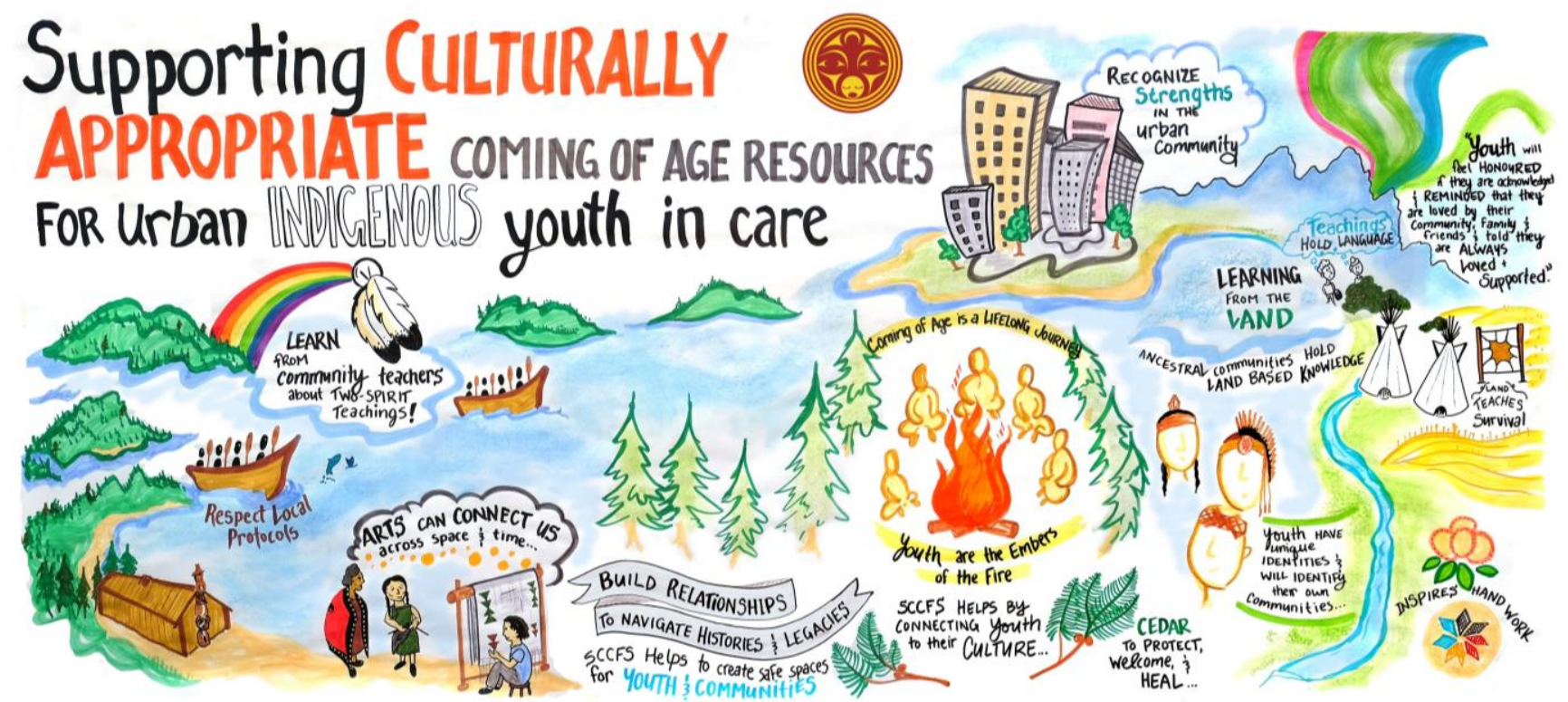

Discussion: Reforming the Circle

Our team held the Knowledge Holder's dinner so that we could ask the urban Indigenous community for guidance in conducting our project Supporting Culturally Appropriate Coming of Age in a Good Way. ${ }^{1}$ The wisdoms shared taught us about the complexities and possibilities involved in supporting urban Indigenous youth in foster or away-from-home care who are coming of age. The Knowledge Holders helped us to answer questions about respectfully engaging with the home/ancestral communities of the youth, how a culturally appropriate coming of age can happen in urban settings where youth may or may not have ancestral ties, what roles Indigenous child welfare organizations like SCCFS have in supporting coming of age ceremonies and rites of passage, and how youth who identify with LGBTQ2S+ identities can be supported in a culturally grounded and safe way (Figure 1).

We learned that (re)connecting to Indigenous coming of age teachings strengthens relationships between Indigenous youth, families, and communities. This relationship help to connect what Nishnaabe Elder Edna Manitowabi refers to as kobade; "a link in a chain —a link between generations, between nations, between states of being, between individuals" (Simpson,

\footnotetext{
${ }^{1}$ Ensuring that this project was done in a "good way" meant that we conducted the research respectfully by honouring Indigenous traditions and spirit, cultivated authentic and lasting relationships, and engaged in meaningful dialogue so that our work could benefit the Indigenous community as a whole (The Aboriginal HIV/AIDS Community-Based Research Collaborative Centre [AHA Centre], 2018).
} 
2016, para. 22). These links are strengthened by the passing of coming-of-age teachings, teachings that have evolved across generations to preserve the strength and resilience inherent in Indigenous ways of knowing and doing.

From the Knowledge Holders, we learned that to develop this strength and resilience, youth need to have access to safe spaces where they can experience their adolescence in ways that are healing, loving, accepting, and empowering. This includes having the space to freely determine and come to know their own identities, learning what "being Indigenous" means to them in their own time, and having access to resources and teachers to become educated on LGBTQ2S+ identities if that is their path. These spaces include role models, Knowledge Holders, and Elders who can help youth with this journey, while at the same time, helping them to learn about their unique histories as Indigenous young people.

The illustration presented in Figure 2 reflects the wisdoms shared by Knowledge Holders and imagines what safe spaces could look like for the youth who are coming of age and communities our project is supporting. This includes specific teachings (e.g., hand work, language, etc.), rites of passage (e.g., hunting, ceremony), cultural protocols, and diverse social, physical, and natural landscapes. It also places the youth at the centre of the conversations, reflecting their role as the future fires of Indigenous Nations.

We learned that part of doing this work in a good way is taking direction from the youth. As one Knowledge Holder shared, “...maybe it's asking them-' what does coming of age mean to you?' Maybe it's cooking, shopping, applying for jobs - a more contemporary version of coming of age." When one of the youth spoke up to share her thoughts on how to do this in a good way, her direction was clear: "In a ceremony,... youth will feel honoured if they're acknowledged and reminded they're loved by their community, family, and friends and told they always will be loved and supported."

Colonization and its impacts on self-determination severely undermined the passing of coming-of-age teachings to successive generations. This is largely due to the disconnection of families and communities from their land and territories (Anderson, 2011; Blanchet-Cohen et al., 2011; Loppie Reading \& Wien, 2009; Markstrom, 2008; Yee, 2009). The Knowledge Holders shared that the communities and teachers who provide support to youth also need safe spaces to heal and (re)connect to their teachings. The reciprocity is evident in the words shared by a knowledge holder: "...these ceremonies have a big impact on healing."

(Re)connecting to coming-of-age teachings is a form of "embodied decolonization" (Risling Baldy, 2018, p. 21), a "returning to," which helps to dismantle the structural determinants that can interfere with the wellness and resilience of Indigenous youth (Markstrom, 2008; Reading, 2018). Indigenous agencies who work to reclaim Indigenous systems of caring for and protecting their children must contend with barriers such as the "imposition of Eurowestern legislation, inadequate access to financial resources, and the continued marginalization of Indigenous knowledge within Euro-Western social work" (Blackstock \& Trocmé, 2005, p. 12). This was illustrated in a reflection from one of our Knowledge Holders: 
We worked with a gentleman from Alberta. He was Ojibway/Cree. Grandfather took him out to a lake. He thought he would be there for four days.... You have all these skills and tools we have given you-how are you going to use them? He thought no one knew where he was at. Grandpa came back six months later. He didn't know how to react. Here's how you survive. Can you imagine Ministry saying, "Where's the child?"

Part of a shared commitment to support urban Indigenous youth in care is recognizing and honouring the diversity in ways of knowing and doing between Nations. Maintaining a focus on what coming-of-age teachings are working to achieve helps to avoid the interference that politicizing the process can have on Indigenous youth wellness. We do this partly by recognizing and honouring that we are doing this work on the territory of the Lekwungen Peoples. Showing respect for Coast Salish protocols, while still supporting the specific, culturally appropriate rites of passage unique to each youth in SCCFS's care, is part of how we are learning to do this work in a good way.

\section{Limitations}

This phase of the project purposefully worked with mainly adult Knowledge Holders from a diversity of Nations. The next phase of the project will focus on the wisdom of the youth Knowledge Holders. The wisdoms shared at this dinner reflects those of the participants and that of the territory where we gathered. We recognize that this work is relevant to many Indigenous communities, and therefore, we engaged with a project framework that would be relevant across different Nations. The findings from our dinner may reflect shared values and beliefs; however they are not intended to speak for all Indigenous Peoples. Because we gathered on Lekwungen territory, we respected the protocols of engagement that have emerged across generations of Indigenous Peoples on these lands. We hope this is reflected in our narrative and illustration, for example with the cedar trees, the lifting of canoe paddles, and the unique land and water relationships. We recognize that each of the territories we reside upon influence our relationships to home, community, and coming of age, and will paint images and tell stories that are special to those places.

\section{Conclusion}

(Re)connecting Indigenous youth in care to culturally appropriate coming-of-age teachings has the potential to be protective to individual and community health and wellness while addressing structural inequities that have historically marginalized Indigenous ways of knowing and doing. We have also presented in our illustrated findings, ways youth can be directly connected to teachings through practices, traditional protocol, and ceremony. The Knowledge Holder's dinner, above all, taught us that the desire and drive to (re)connect youth to coming-of-age teachings is rooted in love for the youth, communities, and culture; they told us, "all youth have a right to these processes." This is a shared journey, navigating a collective resilience, linked through more than 500 generations of ancestors who have walked before. 


\section{References}

The Aboriginal HIV/AIDS Community-Based Research Collaborative Centre (The AHA Centre). (2018). Doing research in a good way [Fact sheet]. https://www.ahacentre.ca/uploads/9/6/4/2/96422574/research_in_a_good_way_finaljune_ 2018.pdf

Anderson, K. (2011). Life stages and native women: Memory, teaching, and story medicine. University of Manitoba Press.

Blackstock, C., \& Trocmé, N. (2005). Community-based child welfare for Aboriginal children: Supporting resilience through through structural change. Social Policy Journal of New Zealand, (24), 12-33. https://doi.org/10.4135/97814129763.n7

Blanchet-Cohen, N., McMillan, Z., \& Greenwood, M. (2011). Indigenous youth engagement in Canada's health care. Pimatisiwin: A Journal of Aboriginal and Indigenous Community Health, 9(1), 87-111.

Brokenleg, M. (2012). Transforming cultural trauma into resilience. Reclaiming Children and Youth, 21(3), 9-13.

Cajete, G. (2000). Native science: natural laws of interdependance (1st ed.). Clear Light.

Chandler, M. J., \& Lalonde, C. E. (1998). Cultural continuity as a hedge against suicide in Canada's First Nations. Transcultural Psychiatry, 35(2), 191-219. https://doi.org/10.1177/136346159803500202

Christensen, J. (2012). Telling stories: Exploring research storytelling as a meaningful approach to knowledge mobilization with Indigenous research collaborators and diverse audiences in community-based participatory research. The Canadian Geographer, 56(2), 231-242. https://doi.org/10.1111/j.1541-0064.2012.00417.x

Claxton, N. (2015). To fish as formerly: A resurgent journey back to the Saanich reef net fishery. University of Victoria.

de Leeuw, S., Cameron, E. S., \& Greenwood, M. L. (2012). Participatory and community-based research, Indigenous geographies, and the spaces of friendship: A critical engagement. The Canadian Geographer/Le Geographe Canadien, 56(2), 180-194. https://doi.org/10.1111/j.1541-0064.2012.00434.x

Flicker, S., Danforth, J., Wilson, C., Oliver, V., Larkin, J., Restoule, J., Mitchell, C., Konsmo, E., Jackson, R., Prentice, T. (2014). "Because we have really unique art": Decolonizing research with Indigenous youth using the arts. International Journal of Indigenous Health, 1(10), 16-34. https://doi.org/10.18357/ijih.101201513271

Kirmayer, L. J., Dandeneau, S., Marshall, E., Phillips, M. K., \& Williamson, K. J. (2011). Rethinking resilience from Indigenous perspectives. The Canadian Journal of Psychiatry, 56(2). https://doi.org/10.1177/070674371105600203

Kovach, M. (2009). Indigenous methodologies: Characteristics, conversations and contexts. Toronto: University of Toronto Press.

Little Bear, L. (2000). Jagged worldviews colliding. Reclaiming Indigenous Voice and Vision, 77-85. 
Little Bear, L. (2009). Naturalizing Indigenous knowledge: Synthesis paper. University of Saskatchewan, Aboriginal Education Research Centre and First Nations and Adult Higher Education Consortium.

Loppie Reading, C., \& Wien, F. (2009). Health inequalities and social determinants of Aboriginal Peoples' health.

Markstrom, C. A. (2008). Empowerment of North American Indian girls. University of Nebraska Press.

McIntyre, A., Chatzopoulos, N., Politi, A., \& Roz, J. (2007). Participatory action research: Collective reflections on gender, culture, and language. Teaching and Teacher Education, 23(5), 748-756. https://doi.org/10.1016/j.tate.2006.12.025

McIvor, O., Napoleon, A., \& Dickie, K. M. (2009). Language and culture as protective factors for at-risk communities. Journal de Sante Autochtone, November, 6-25. https://doi.org/10.18357/ijih51200912327

Mendenhall, T. J., \& Doherty, W. J. (2007). Partners in diabetes: Action research in a primary care setting. Action Research, 5(4), 378-406. https://doi.org/10.1177/1476750307083722

Reading, C. (2018). Structural determinants of Aboriginal peoples' health. In N. M. Lindsay, M. Greenwood, \& S. de Leeuw (Eds.), Determinants of Aboriginal Peoples' Health: Beyond the social (2nd ed., pp. 3-17). Canadian Scholars' Press.

Risling Baldy, C. (2018). We are dancing for you: Native feminisms and the revitalization of women's coming-of-age ceremonies. University of Washington Press.

Saldana, J. (2014). Coding and analysis strategies. In P. Leavy (Ed.), The Oxford handbook of qualitative research (pp. 1-49). Oxford University Press.

Surrounded by Cedar Child and Family Services (SCCFS). (2018). The creation story of Surrounded by Cedar Child \& Family Services. Victoria, BC.

Simpson, L. B. (2016). Land and reconciliation: Having the right conversations. Electric City. https://www.electriccitymagazine.ca/2016/01/land-reconciliation/

Statistics Canada. (2011). Aboriginal peoples: Fact sheet for Canada. https://www.aadncaandc.gc.ca/eng/1376329205785/1376329233875

Suleiman, A. B., Soleimanpour, S., \& London, J. (2006). Youth action for health through youthled research. Journal of Community Practice, 14(1-2), 125-145. https://doi.org/10.1300/J125v14n01

Wilson, S. (2008). Research is ceremony: Indigenous research methods. Fernwood Publishing.

Truth and Reconciliation Commission of Canada. (2015). Honouring the truth, reconciling for the future: Summary of the final report of the Truth and Reconciliation Commission of Canada.

http://www.trc.ca/assets/pdf/Honouring_the_Truth_Reconciling_for_the_Future_July_23 _2015.pdf

Yee, J. (2009). Introduction. Our Schools, Our Selves, 18(2), 1-6. 